\title{
AESIS: a support tool for the evaluation of sustainability of agroecosystems. Example of applications to organic and integrated farming systems in Tuscany, Italy
}

\author{
Gaio Cesare Pacini, Giulio Lazzerini, Concetta Vazzana \\ Department of Plant, Soil and Environmental Science, University of Florence, Italy
}

\begin{abstract}
Agricultural researchers widely recognise the importance of sustainable agricultural production systems and the need to develop appropriate methods to measure sustainability on the farm level. Policy makers need accounting and evaluation tools to be able to assess the potential of sustainable production practices and to provide appropriate agro-environmental policy measures. Farmers are in search of sustainable management tools to cope with regulations and enhance efficiency. This paper presents the outcomes of applications to organic and integrated farming of an indicator-based framework to evaluate sustainability of farming systems (Agro-Environmental Sustainability Information System, AESIS). The AESIS was described together with a review of applications dating from 1991 in a previous paper. The objective of the present paper is to present the AESIS application to organic and integrated farming systems in Val d'Elsa (Tuscany) and discuss how it is adapted for application to ordinary farms. The AESIS is organised into a number of environmental and
\end{abstract}

Correspondence: Gaio Cesare Pacini, piazzale delle Cascine 18, 50144 Firenze, Italia. Tel: +39.055 .3288252 , Fax: +39.055 .332472 .

E-mail: gaiocesare.pacini@unifi.it

Key words: indicator-based framework, farming systems, organic agriculture, sustainability evaluation.

Received for publication: 29 November 2010.

Accepted for publication: 29 November 2010.

Acknowledgements: the study presented in this paper was funded by the project "EQUAL T.R.E.N.O. IT-S-MDL-263" within the framework of the EU Initiative EQUAL of the European Social Fund and the Italian Ministry of Labour and Social Policies. The authors acknowledge with thanks Giovanna Casella and Roberto Vivoli for their support in collecting data and farmers from Val d'Elsa area for their helpful contribution.

(C) Copyright G.C. Pacini et al., 2011

Licensee PAGEPress, Italy

Italian Journal of Agronomy 2011; 6:e3

doi:10.4081/ija.2011.e3

This article is distributed under the terms of the Creative Commons Attribution Noncommercial License (by-nc 3.0) which permits any noncommercial use, distribution, and reproduction in any medium, provided the original author(s) and source are credited. production systems. For each system, environmental critical points are identified with corresponding agro-environmental indicators and processing methods. Possible solutions to sustainability issues and critical points of relevance to the agricultural sector of the local economic and agro-ecological zone are formulated by including an experimental layout, identifying indicator thresholds and by defining management systems with corresponding policy measures. Alternative solutions are evaluated by calculating and measuring the relevant indicators.

The outcomes of the AESIS applications are discussed with specific relevance to the operational adoptability of AESIS to ordinary, agritouristic farms managed with the organic and the integrated production method, respectively. The AESIS framework proved to be sufficiently flexible to meet the requirements for ordinary farm applications while keeping a holistic perspective and considering pedo-climatic and production factors on different spatial scales.

\section{Introduction}

Indicators are often used to measure sustainability performance on different spatial scales: these indicators may either be strongly ecological in focus and very detailed, or they may be more policy-oriented. Therefore, indicators have been developed that differ greatly in information content and in the degree of condensation of this information (Braat, 1991). In order to guide decision-makers in taking coherent choices based on the sustainability principles, indicators can be embedded in a logical sequence of phases, often called framework.

Currently, there is a vast range of indicator-based frameworks to evaluate sustainability of both farming systems (FSs) and land-use. Some focus on environmental impact (for an example, see the critical review of 12 indicator-based methods reported by Van der Werf and Petit, 2002), whilst others hold a stronger holistic component and also consider socio-economic aspects. Examples of the latter type of frameworks, broadly applied in the agricultural sector, include the International Framework for Evaluating Sustainable Land Management (FESLM, Smith and Dumanski, 1994), the framework of the Research Network on Integrated and Ecological Arable Farming Systems for EU and Associated Countries (Vereijken, 1999), the Checklist for Sustainable Landscape Management (Van Mansvelt and Van der Lubbe, 1999), the Problem-Solving Framework for Modelling Sustainability Issues (Weersink et al., 2002) and the Framework for Assessing the Sustainability of Natural Resource Management Systems (MESMIS, López-Ridaura et al., 2002).

In general, the above-mentioned frameworks are based on a strong conceptual background with a complex organisation of the evaluation protocols. However, due to either cryptic theoretical superstructures or to a narrow range of application purposes, their direct practical applicability to ordinary farms is questionable. For the purpose of this paper, 
an ordinary farm is defined as a farm that is not a model or an experimental farm, i.e. a common farm. For more details on the differences between an experimental and an ordinary farm, reference is made to Lewis (1836). More research effort is required to optimise the balance between conceptual soundness and operantionalability. Besides, indicators currently used often lack reference to different hierarchical spatial levels and do not consider pedo-climatic variability.

In a previous paper, an indicator-based framework to evaluate sustainability of farming systems was presented together with a review of its applications dating from 1991 (Pacini et al., 2009). The framework, entitled Agro-Environmental Sustainability Information System (AESIS), is a holistically designed information system to support decisions at different levels in the agricultural sector.

The AESIS (current formulation of the framework) and its previous version (the EAIS, environmental accounting information system; Pacini et al., 2000; Pacini et al., 2003) have been developed since 1991 from previous experiences (Pileri, 1992; Vazzana et al., 1997; Vereijken, 1999) aimed at finding the right balance between a range of different application purposes and the level of complexity of indicators, including different spatial scales, production and pedo-climatic factors. During this time span, the framework has been developed through the incorporation of new elements, including those retrieved from the above-mentioned studies. To our knowledge, in the literature of indicator-based frameworks for farm evaluation of sustainability, there are no examples of applications comparing integrated and organic, vine-olive production oriented FSs.

In this paper, the application of AESIS to two ordinary farms conducted with the organic and the integrated farming method, respectively, is presented in detail. The two farms are oriented towards vine and olive production and are representative of relevant production systems under the organic and the integrated methods in Val d'Elsa, Tuscany.

In previous publications, the application of AESIS for modelling decisions of integrated ecological-economic farm management was presented (Pacini et al., 2003; Pacini et al., 2004a; Pacini et al., 2004b). In the present paper, the adaptation of AESIS for the application to ordinary farms is discussed. Concerning adaptation of AESIS for ordinary farm applications, the challenge of this paper is to reveal the didactic power of AESIS; under this perspective the focus of the present article is not on indicator methods and calculations but on the AESIS logical sequence of phases and how they should be interpreted to facilitate the process of sustainability evaluation when large samples of ordinary farms are involved. The two farms presented are used as examples for the application of the complete sequence of AESIS phases, while results of indicators should be interpreted considering the limitations due to such a small sample.

\section{Materials and Methods}

\section{Farms and sites}

The AESIS was applied to two ordinary farms located in Val d'Elsa, an area about $40 \mathrm{~km}$ southwest of Florence in Central Tuscany (latitude $44^{\circ} \mathrm{N}$ ) that focuses primarily on vine production. The climate of Val d'Elsa is Mediterranean, with an average annual rainfall of $650 \mathrm{~mm}$. Although a high quality production is a standard practice in Val d'Elsa, large parts of this sub-region are still excluded from the richest Tuscan wine markets, which give even more importance to alternative, multifunctional activities such as agritourism.

As indicated by the report of the regional Tuscan environmental action plan (Regione Toscana, 2003), the quality of the environment in Val d'Elsa is higher than the regional average, which supports the development of agritourism. However, such high standards of quality must be kept in close relationship with sustainable farming practices.
In order to obtain outcomes of practical use for the entire Val d'Elsa area, while maintaining a high resolution of the analysis, two farms were selected as representative of production systems under organic and integrated production according to the following criteria: i) Farmlands with the soil types, land morphology, and hydrological conditions characteristic of the area; ii) farms with a land use similar to the average area of those local farms employing at least one full time worker (ISTAT, 2000). La Sorbigliana is an organic farm located in the municipality of Castelfiorentino that has vineyards, olive trees, and a rotation of arable crops. In 2001, the farm started following organic management techniques in accordance with the EU Regulation 2092/91. La Sorbigliana has a total land area of 38.90 ha, cultivates 2.31 ha of vineyards, 4.83 ha of olive trees, 18.04 ha of arable crops, 4.82 ha of fallow and unproductive land, and 8.90 ha of woodland.

Poggio ai Grilli, located in the municipality of Gambassi Terme, is an integrated farm that cultivates fruit and grain in addition to vineyards and olive trees. It follows integrated production rules, as defined by the corresponding agri-environmental measure of the 2000-2006 Tuscany rural development plan. Of the farm's 19.58 ha, vineyards are cultivated on 9.73 ha, olive trees on 0.30 ha, corn on 3.60 ha, and a variety of fruit trees (pear, apple, peach, plum, and apricot) on 0.83 ha.

Organic agriculture is supported by a holistic approach, which is not present in integrated agriculture as it is performed today. Moreover, in organic farming the use of synthetic agrochemicals is strictly forbidden, while integrated farming rules allow the application of synthetic fertilizers as well as of synthetic pesticides subject to a threshold criterion.

To perform a detailed spatial scale analysis, each farm was divided into several different sites according to land morphology and soil conditions (Table 1). Under the AESIS framework a site is defined as a farm spatial sub-unit having relatively homogeneous slopes, soil types, water table and climate. Within a site, there could be one or more crops. Data for the AESIS application were collected on farm, site and site-representative fields of each crop.

\section{The AESIS approach}

An in-depth description of AESIS is given in Pacini et al. (2009). Here, the AESIS procedural phases are summarized with the aim to recall the AESIS general features and show how it can be applied to ordinary farms. The main feature of the indicator framework is the importance given to different spatial scales (farm, site and field), to the production and pedo-climatic factors, and to the holistic view of the agro-ecosystem.

The framework has been developed to undertake different tasks ranging from modelling approaches, to long-term experiments in experimental stations, to farm-level management systems and policy monitoring. Besides, as explained in Pacini et al. (2009), the framework has been designed and tested to be coherent with the current European financial accounting model (FADN; EC, 2009).

The AESIS was aimed at finding the right balance between a range of different application purposes and the level of complexity of indica-

Table 1. Farm and site characteristics and areas.

\begin{tabular}{lccrc}
\hline Farm/site & $\begin{array}{c}\text { Land } \\
\text { morphology }\end{array}$ & $\begin{array}{c}\text { Soil } \\
\text { texture }\end{array}$ & $\begin{array}{c}\text { AAU* } \\
\text { (ha) }\end{array}$ & $\begin{array}{c}\text { Total area } \\
\text { (ha) }\end{array}$ \\
La Sorbigliana & & & 25.18 & 38.90 \\
Site SRB1 & Plain & Sandy clay loam & 9.40 & 13.46 \\
Site SRB2 & Hilly & Sandy loam & 15.78 & 19.64 \\
Site SRBwood & Hilly & - & 0.00 & 5.80 \\
Poggio ai Grilli & & & 16.70 & 19.58 \\
Site PG1 & Plain & Loam & 12.30 & 13.62 \\
Site PG2 & Hilly & Clay loam & 4.40 & 5.96 \\
\hline
\end{tabular}

*Agricultural area used. 
tors. Agro-environmental indicators can be calculated, simulated with models or directly measured with different levels of detail, in proportion to the aims of the evaluation exercise. The procedural phases to apply the framework are reported in Table 2, so as they were modified from Weersink et al. (2002), and explained in the following sections.

\section{Phase 1. Definition of the sustainability issues}

Being a framework oriented to a problem-solving approach, the AESIS application procedure was initiated with gathering of already available information on the issues related to sustainability in the region (AESIS sub-phase 1.1). Thereafter, specific environmental critical points, that connect issues with the farm agroecosystem, were pinpointed (sub-phase 1.2). The AESIS was organised into several environmental and production systems, as well as their respective subsystems. Within each module, a number of environmental and production processes take place, which, in turn, affect the relevant critical points. A set of agro-environmental indicators for the quantification of the performance of the management of each environmental and production process in the agro-ecosystem was then identified (sub-phase 1.3).

\section{Phase 2. Problem-solving approach to the sustainability issues}

The AESIS was developed not only to assess the sustainability of farms but also to evaluate possible production alternatives in order to improve the environmental performances of production processes. The first step of this process consisted of designing a comparison layout where current practices under evaluation were compared with different management systems and with scientifically determined sustainability thresholds (sub-phase 2.1). The thresholds are identified for each single indicator. They are part of the solution to the sustainability problem and determine the extent to which decision-makers change their strategies in order to attain the goals they represent (sub-phase 2.2). In the case of Val d'Elsa the comparison layout included the comparison between integrated and organic agriculture as well as comparisons of the integrated and the organic farming systems (IFS and OFS, respectively) with thresholds.

Thereafter, the management systems indicated in the comparison

Table 2. AESIS procedural phases (modified from Weersink et al., 2002).

\section{Phase 1. Definition of the sustainability issues}

1.1. Identify issues related to sustainability in the region

1.2. Identify critical points and connect them to farm environmental and production systems

1.3. Choose indicators

Phase 2. Problem-solving approach to the sustainability issues

2.1. Formulate a comparison layout (e.g., analysis of farm performances with thresholds, comparisons of different management systems/techniques on the same farm, comparisons between farms, comparisons between farm model simulation results)

2.2. Identify indicator thresholds (or critical limits, sustainability targets)

2.3. Describe the management systems (e.g., organic, integrated, environmentally-friendly, best available technologies etc.) applied in the comparison layout

2.4. Identify potential policy measures

\section{Phase 3 . Evaluating alternative solutions}

3.1 Select calculation methods of indicators in proportion to the evaluation purpose

3.2. Integrate indicators in a farm simulation model (optional)

3.3. Measure indicators

3.4. Present and analyze results layout (i.e., organic and integrated) were described (sub-phase 2.3). The next AESIS step involving the identification of policy measures (sub-phase 2.4) was not enforced, as it applies only to farm modelling studies (Pacini et al., 2009).

\section{Phase 3. Evaluating alternative solutions}

In this phase of the evaluation procedure, the calculation methods of the indicators were selected following a criterion of proportionality to the evaluation purpose (sub-phase 3.1). For example, indicator processing methods for policy auditing have to be applied to a large number of farms and as such may be based on simple presence/absence observations, whereas some indicators for research and policy planning are calculated for selected representative farms by applying complex, ecological-environmental models with high data input requirements such as GLEAMS (Knisel, 1993) or CropSYST (Stockle et al., 2003) (for examples of applications of these two models within the AESIS framework, reference is made to Pacini et al., 2003, and Moriondo et al., 2010, respectively). In the two farms under survey we chose to apply a combination of in-field observations and simple simulation modelling. For an application to ordinary farms such as that presented here we discarded any farm integrated modelling exercise (subphase 3.2).

Finally, indicators were measured (sub-phase 3.3) and results were presented (sub-phase 3.4). This is particularly important, as the evaluation exercise would be meaningless if the beneficiaries of the information were unable to gain a clear idea of the results of the exercise and the implications on their decisions. A number of possible options exist to show the results. However, as discussed in Pacini et al. (2009), trade-off curves and spider diagrams are the most common in indicator framework studies.

\section{Results}

In the next sections, the results of the case-study application are presented by following the entire process phase by phase, as reported in Table 2.

\section{Phase 1. Definition of the sustainability issues}

The definition of local sustainability issues was initiated from the review of the situation in Val d'Elsa given by the report on the state of the environment in the 2004-2006 Tuscany Regional environmental action plan (Consiglio Regionale della Regione Toscana, 2004, subphase 1.1). In the second Annex of the plan, environmental analyses of homogeneous areas (including Val d'Elsa) in Tuscany were summarised by reporting the results of 18 landscape indicators, ranging from agricultural pressure to demographic and production density, tourism intensity, $\mathrm{CO}_{2}$ emissions, exposition to air pollution, production of wastes and others. Environmental criticity was measured for 16 of these indicators. In the case of Val d'Elsa, the indicator criticity ranged from absent (1 indicator), very low (4), low (10, including $\%$ of fertilised agricultural area used, AAU, and $\%$ of AAU treated with pesticides) and average (1), as compared to regional averages of Tuscany. In general, Val d'Elsa revealed a very high level of environmental quality combined with an extensive type of agricultural practice.

This data was used to identify sustainability issues in Val d'Elsa. The situation depicted by the above-mentioned indicators on the regional level (i.e., environmental quality and low pressure from agricultural activities) adapt well to multi-functional activities such as agritourism: in fact, agri-touristic, family-run farms are common in the area, with many oriented towards vine and olive production. Here a sustainability issue arises on how to combine intensive production sys- 
tems (especially vine) with the need to guarantee environmental health on the farm level, and more generally on how to maintain the quality of the environment. Hence, the next step consisted of identifying the farm environmental critical points (sub-phase 1.2). Thereafter, corresponding measurable indicators were chosen with special reference to vine production under a systemic approach (sub-phase 1.3).

In columns a, b, $c$ of Table 3 , the results of these two steps (sub-phases 1.2 and 1.3) are reported. Starting from the AESIS general framework presented in Pacini et al. (2009), critical points were selected from the complete AESIS list coherently with the identified sustainability issue (reported in italics). To maintain a holistic view of the FSs, all farm environmental systems were included in the analysis (italics character). Following the proportionality principle, and considering the scale of family-run, ordinary farms, a minimum of one indicator per environmental system was chosen (italics character). A total of 8 indicators were applied.

\section{Phase 2. Problem-solving approach to the sustainability issues}

The second macro-phase of AESIS consisted of finding potential solutions to the conflict vine intensive production versus promoting environmental quality for farm agri-touristic activities and the maintenance of ecological health in Val d'Elsa. First, a comparison layout was settled by choosing two representative farming systems run with organic and integrated management, respectively (sub-phase 2.1). Previous studies focusing on pesticide impact in the area (Lotti et al., 2006), revealed that conventional FSs provoke considerably higher risks than those linked to OFSs or IFSs, and were, therefore, discarded from the comparison scheme. Both farms conduct agri-touristic activities. Besides farm comparisons, which permitted the collection of information on how to solve the issue on the farm level, comparisons of single farms with environmental thresholds were also settled in order to study how representative farms impact on ecological health of Val d'Elsa. Threshold values are shown in Table 4 (right-hand-side columns, sub-phase 2.2) together with corresponding bibliographical sources and farm results.

Next, the selected management systems were defined, both conceptually and legally (sub-phase 2.3). Following Mannion (1995), organic farming is a holistic view of agriculture that aims to reflect the profound interrelationship that exists between farm biota, its production and the overall environment. From a legal viewpoint, the OFS analyzed in this study complies with the stipulation of the EU Regulation

Table 3. Complete AESIS list of environmental critical points, systems, indicators and relevant procedures with corresponding selections for sustainability evaluation of farming systems in Val d'Elsa, Tuscany (in italics critical points, indicators and procedures selected for this study from the complete AESIS list, Pacini et al., 2009).

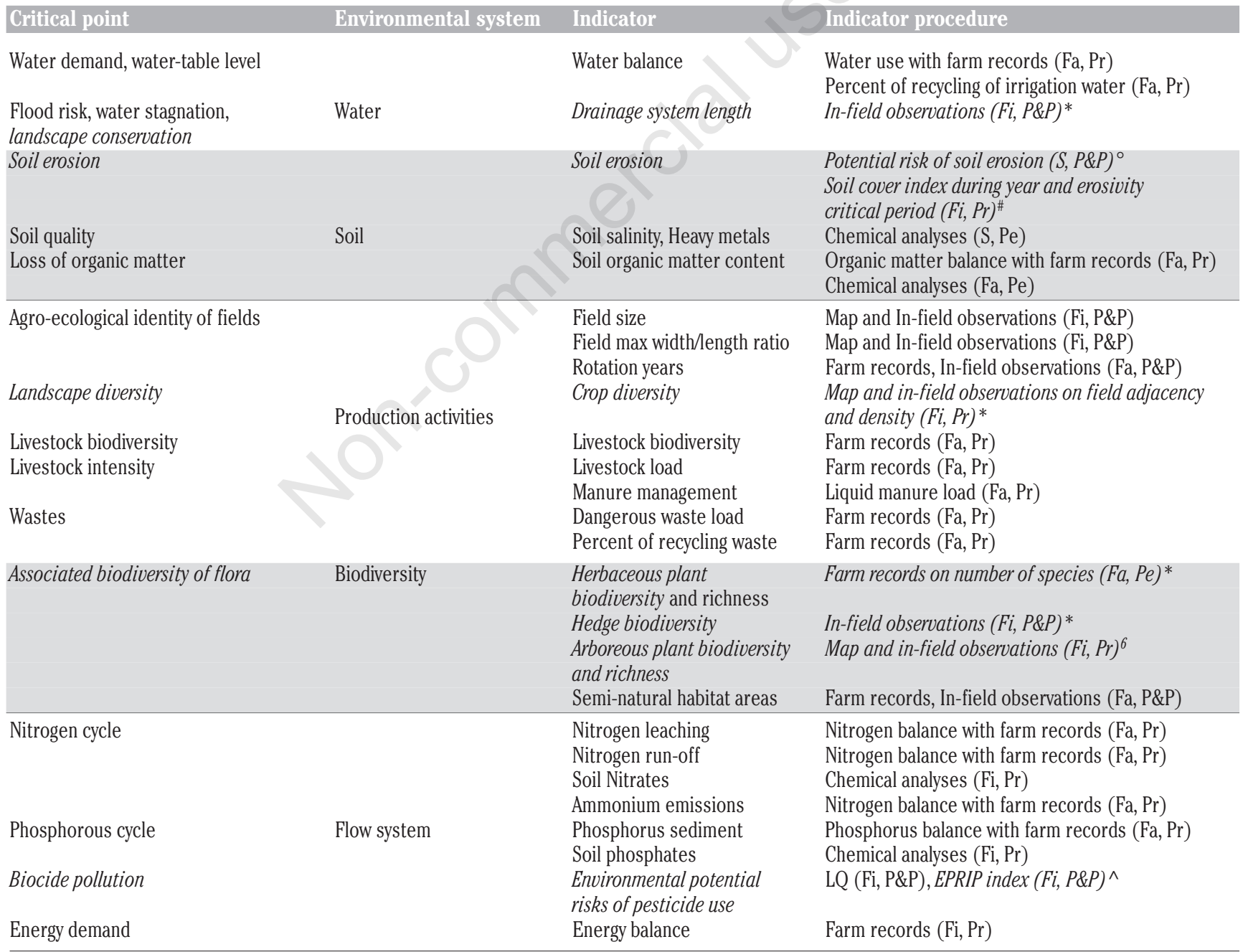

Fi, field; S, site; Fa, farm; P\&P, production and pedo-climatic factors; Pr, production factor; Pe, pedo-climatic factor; LQ, leached quantity; EPRIP, environmental potential risk indicator for pesticides. *Complete procedures are presented in Pacini (2003), pages 148-152; ${ }^{\circ}$ complete procedure is presented in Manrique (1986); ${ }^{\sharp}$ complete procedure is presented in Vereijken (1994), page 87; ^ complete procedure is presented in Padovani et al. (2004). 
2092/91 (EEC, 1991) on organic production of agricultural products. For IFSs, the definition of El Titi (1992) was selected, which describes IFSs as a holistic pattern of land use which integrates natural regulation processes with farming activities to achieve maximum replacement of off-farm inputs and to sustain farm income. The IFS analysed in this study met the requirements of the integrated farming code of the 20002006 Tuscany Region rural development plan (TRRDP), which enforced the EU Regulation 1257/99 (EC, 1999).

\section{Phase 3. Evaluating alternative solutions}

In this phase, calculation methods of indicators were selected that met the requirements of the present type of application purpose (i.e., ordinary farms, sub-phase 3.1). One procedure was selected for each indicator identified in the definition phase of the sustainability issues (Table 3, Column d, in italics). The method and procedure sources, as well as the descriptions are indicated in Table 3. Indicators were measured and relevant results are shown in Table 4 (sub-phase 3.3). Results show that the OFS on La Sorbigliana achieved a higher performance in terms of planned (arboreous plant biodiversity, APB, and hedge biodiversity, HB) and associated (herbaceous plant biodiversity, HPB) biodiversity, and environmental potential risk indicator for pesticide use (EPRIP). In contrast, the IFS on the Poggio ai Grilli farm showed better results in terms of crop diversity (CD), drainage system length (DSL), potential risk of soil erosion (PRSE) and soil cover index (SCI). By examining the site level, a large within-farm heterogeneity can be noticed with regard to the OFS indicators of APB, DSL and EPRIP, and the IFS indicators of HB, DSL and EPRIP. OFS EPRIP heterogeneity is due to the fact that the only treated crops, i.e. vine and olive, were located in Site 1. DSL was found to be equal to zero in the flat sites of both the organic and IFSs.

As far as comparisons with environmental thresholds are concerned, the OFS showed non-sustainable results for DSL, PRSE and SCI. The latter two need to be interpreted in a combined manner as PRSE provides a measure of soil erodibility and rainfall erosivity but does not consider management practices, while SCI represents the impact of farm choices regarding the land use (Lazzerini and Vazzana, 2005; Vazzana et al., 1997; Vereijken, 1999). In the OFS, notwithstanding the above-threshold risk of soil erosion (PRSE of 9 against a threshold value of 8), the land use does not allow for a high enough level of soil cover to avoid erosion phenomena (SCI of 51\% against a threshold value of $60 \%$ ). In the case of the IFS, the opposite applies. Even if the risk of soil erosion is higher than that of OFS (i.e. PRSE equal to 10 vs. 9 ), the combination of the use of living mulches in vineyards with the land use allowed for sustainable levels of SCI (SCI equal to 84\%). Besides PRSE, other non-sustainable values were reported for APB, HB

Table 4. Results of environmental indicators on site and farm scales of the case-study farms.

\begin{tabular}{|c|c|c|c|c|c|c|c|c|c|}
\hline & Int & rated & & & anic f & & & TV & TT \\
\hline & Site 1 & Site 2 & Farm ${ }^{\circ}$ & Site & Site 2 & od site & Farm & & \\
\hline Drainage system length, m/ha & 520 & 0 & 383 & 191 & 0 & - & 71 & $140^{\mathrm{a}}$ & Lower* \\
\hline Potential risk of soil erosion, score/ha & 9 & 11 & 10 & 9 & 9 & - & 9 & $8^{b}$ & Upper $^{\circ}$ \\
\hline Soil cover index, $\%$ & 78 & 100 & 84 & 46 & 54 & - & 51 & $60^{c}$ & Lower \\
\hline Crop diversity, score/ha & 1295 & 877 & 1182 & 1164 & 338 & - & 646 & $30^{\mathrm{d}}$ & Lower \\
\hline Herbaceous plant biodiversity, score/ha & 91 & 98 & 93 & 169 & 112 & - & 138 & $48^{\mathrm{e}}$ & Lower \\
\hline Hedge biodiversity, m/ha & 41 & 0 & 30 & 78 & 137 & 0 & 115 & $60^{f}$ & Lower \\
\hline Arboreous plant biodiversity, $\%$ & 0 & 0 & 0 & 0 & 6 & 58 & 12 & $5^{g}$ & Lower \\
\hline EPRIP, score/ha & 80 & 120 & 92 & 27 & 0 & 0 & 9 & $81^{\mathrm{h}}$ & Upper \\
\hline
\end{tabular}

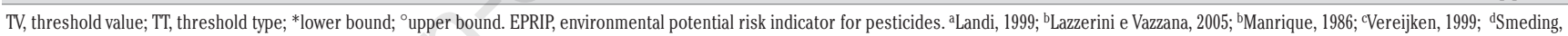
1995; 'Pacini, 2003; fSchotman, 1988; sVereijken, 1999; 'Padovani et al., 2004.

Table 5. Action table with indications of threshold compliance per indicator and of sustainable farming practices on site and farm scale in studied farms.

\begin{tabular}{|c|c|c|c|c|c|c|c|c|}
\hline & $\begin{array}{l}\text { Inte } \\
\text { Site } 1\end{array}$ & $\begin{array}{l}\text { grated } 1 \\
\text { Site } 2\end{array}$ & Farm ${ }^{\operatorname{arm}}$ & Site 1 & $\begin{array}{l}\text { Organ } \\
\text { Site } 2\end{array}$ & $\begin{array}{l}\text { lic farm } \\
\text { Wood site }\end{array}$ & Farm & Proposed intervention \\
\hline Drainage system length & ;) & ;: & (:) & (:) & ;: & - & : & $\begin{array}{l}\text { Construction of the drainage system on site } 1 \\
\text { of the integrated farm and site } 2 \text { of the organic farm }\end{array}$ \\
\hline Potential risk of soil erosion & : : & 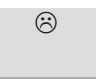 & : : & : : & : : & - & (2) & $\begin{array}{l}\text { Introduction of living mulch on sites } 1 \text { and } 2 \text { of the } \\
\text { organic farm }\end{array}$ \\
\hline Soil cover index & ;:) & ;) & ;:) & : & : $:$ & - & (:) & \\
\hline Crop diversity & ;) & (:) & (:) & (:) & (:) & - & (:) & - \\
\hline Herbaceous plant biodiversity & ;:) & ;) & ;:) & ;:) & ;:) & - & ;) & - \\
\hline Hedge biodiversity & : : & (:) & : : & (:) & (:) & - & (:) & $\begin{array}{l}\text { Planting hedges on sites } 1 \text { and } 2 \text { in the integrated } \\
\text { farm }\end{array}$ \\
\hline Arboreous plant biodiversity & : & 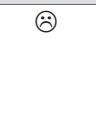 & : & : : & ;) & ;) & (:) & $\begin{array}{l}\text { Reforestation of part or all of un-cultivated land in } \\
\text { the integrated farm (1.1 ha on site } 1 \text { and } 1.5 \text { on site } \\
\text { 2), and part of uncultivated land of site } 1 \text { in the } \\
\text { organic farm }\end{array}$ \\
\hline $\begin{array}{l}\text { Environmental potential risk } \\
\text { indicator for pesticides }\end{array}$ & ;) & (:) & (2) & (:) & (:) & ;) & ;) & $\begin{array}{l}\text { Reduction in the number of pesticide treatments } \\
\text { (for mancozeb and tebuconazole) }\end{array}$ \\
\hline
\end{tabular}


and EPRIP. In the majority of cases, the non-sustainability of the system depended univocally on all corresponding site values. However, for DSL, site values of some indicators showed opposite results when compared to the thresholds (APB for OFS and EPRIP for IFS). Results of threshold comparisons were visualised for the last step of this phase by drawing farm-specific spider diagrams (Figure 1) and by providing a corresponding action table to advice farmers (Table 5) (sub-phase 3.4).

\section{Discussion}

In this section, the AESIS method application to ordinary farms is discussed with reference to the relevant phases (Table 2) in the procedure; thereafter a commentary on the different impacts of organic and IFSs for the two farms under survey was provided. The main challenge to the application of AESIS to projects including large samples of ordinary farms is to combine a systemic evaluation of FSs with the scarcity (financial and time) of resources that can be allocated for each farm. Extensive surveys accounting for high numbers of farms are subject to fund and labour dispersion. Maintaining a holistic view of the agroecosystem involves taking into consideration the entire range of sectorial environmental critical points and farm environmental systems, while simultaneously assigning specific attention to those that are considered to be of local importance. In this study, the solution adopted in two pilot farms was to identify a small set of indicators covering all the environmental systems with at least an indicator (AESIS Phase 1), and to choose simplified calculation procedures (Phase 3 ).

In Phase 2, the comparison layout was constructed by reducing the range of investigated management systems/practices to only two alternative options (i.e., OFS and IFS). Such a choice may have large impact on the process of selection of solutions. If other management solutions such as environmental management systems (EMS) or conventional farming were included in the analysis, then this would result in a more robust solution space for the sustainability issues identified in Val d'Elsa, but would also cost more in terms of financial requirements for the survey. This is an important "political" point that needs to be considered in the settlement phase of the sustainability evaluation exercise. Another issue arising with regard to Phase 2 is the collection of information on environmental thresholds. Irving and Moncrieff (2004) stated that environmental thresholds should be selected according to local pedo-climatic and production characteristics. In the present study, the thresholds applied were retrieved from other studies carried out in Tuscany. As a result, a given level of approximation in terms of outcomes of the comparison had to be accepted.

For the purpose of simplifying the AESIS application, two steps were discarded, that is the identification of policy measures (sub-phase 2.4) and the integration of indicators in a farm simulation model (sub-phase 3.2).

The AESIS was constructed with three different application purposes: i) detailed model-based analyses for the evaluation of organic, integrated and conventional farming systems (OFS, IFS and CFS, respectively) and for policy planning; ii) application to micro-farms on an long term experimental station to prototype organic arable FSs and to compare organic and conventional farming practices; iii) application to ordinary farms for the development of farm environmental management systems (EMS) and for evaluating organic, integrated and conventional FSs. Although a number of nuances occur between these three groups, each corresponds to the needs of relevant end-user groups, namely policy-makers, technicians and farmers, respectively. Hence, particular attention focussed on selecting transparent and meaningful-for-farmer indicators as well as straightforward result visualisation tools, such as action tables (Table 5) and spider diagrams (Figure 1), largely applied in the literature (e.g., Nicholls et al., 2004).

In conclusion, since the AESIS method was adapted for applications

\section{Integrated farm HPB}
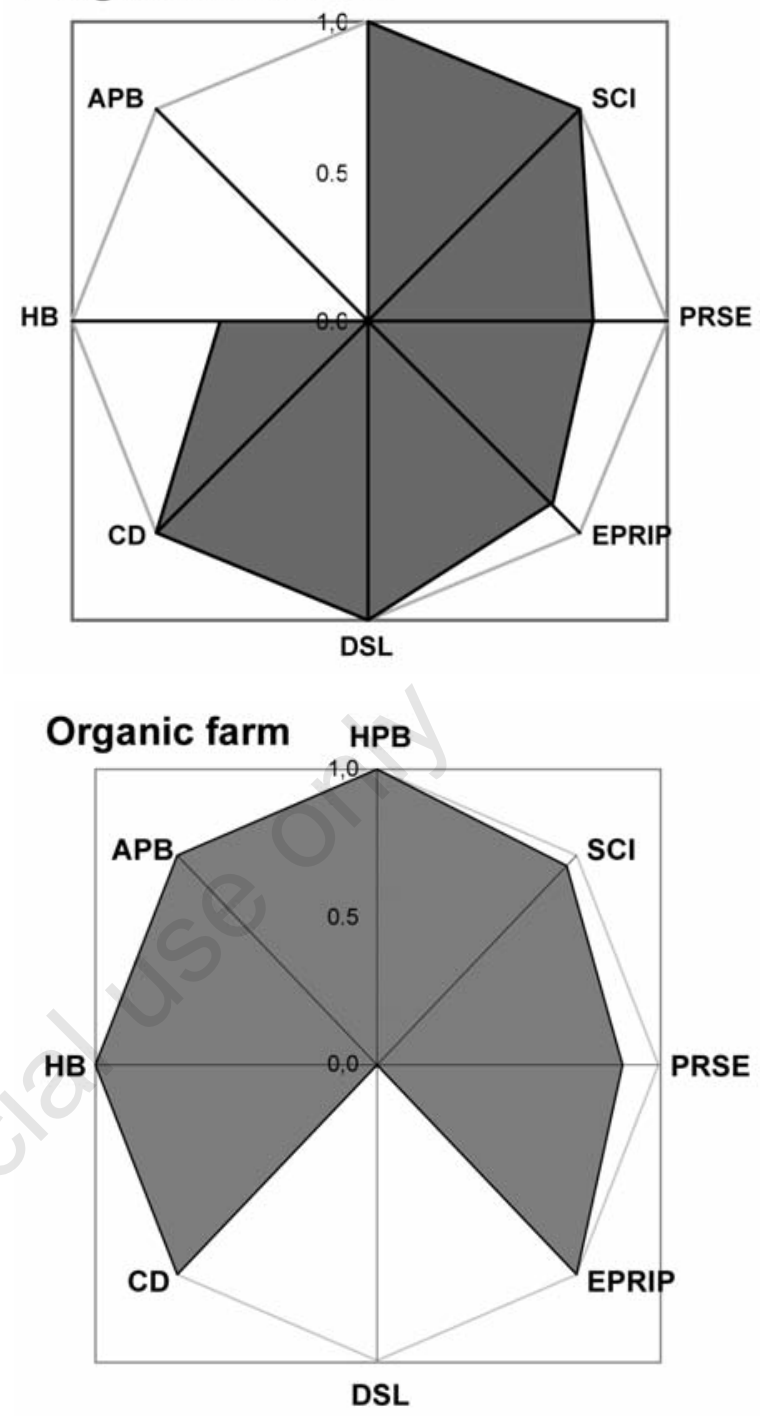

Figure 1. Spider diagrams of agro-environmental results of the organic and IFS. Non-sustainable and sustainable performances are visualised in light and dark grey, respectively. The score 1 corresponds to the threshold value of corresponding indicators. $\mathrm{HB}$, hedge biodiversity; APB, arboreous plant biodiversity; HPB, herbaceous plant biodiversity; SCI, soil cover index; PRSE, potential risk of soil erosion; EPRIP, environmental potential risk indicator for pesticides; DSL, drainage system length; CD, crop diversity.

in ordinary farms, it proved to be sufficiently flexible for both the particular research and end-user requirements of this type of application purpose. Financial and time costs were also measured. Financial costs amounted to about 120.00 Euros per farm due to soil chemical analyses; personnel employment for AESIS application was as reported in Table 6 . Results on financial and time costs are compatible to those previously reported by farmers' organisations (Lazzerini, 2001).

Results of agro-environmental indicators highlight the betweenfarm differences in terms of impact of organic and IFSs, and of withinfarm heterogeneity on site scale due to the combination of pedo-climatic and production factors. The OFS, in general, showed better results than the IFS. However, especially for those management areas not constrained by organic agriculture legislation, performance was found to be worse than that of IFS, and sometimes also scarce in terms of com- 
Table 6. Action table with indications of threshold compliance per indicator and of sustainable farming practices on site and farm scale in studied farms.

AESIS phase

Definition of the sustainability issues

Problem-solving approach to the sustainability issues

Evaluating alternative solutions AESIS step lime (days)

Identify issues related to sustainability

Identify detailed critical points and connect them to farm

environmental and production systems

Choose indicators

Settle a comparson layout

Identify indicator thresholds

Describe management systems

$\begin{array}{lc}\text { Select calculation methods of indicators proportional to the evaluation purpose } & 1.0 \\ \text { Measure indicators: } & \\ \text { data collection on farm structure } & 0.5 \\ \text { crop record cards } & 0.5 \\ \text { field data collection on biodiversity } & 2.0 \\ \text { collection of soil samples } & 0.5 \\ \text { data processing } & 4.5 \\ \text { Present and analyse results } & 0.5 \\ & 12.5\end{array}$

Consiglio Regionale della Regione Toscana, 2004. Deliberation n. 29 of 2 March 2004, "Piano Regionale di Azione Ambientale della Toscana 2004-2006”. BURT n. 15 del 14 aprile 2004, Part 2, Suppl. n. 67.

EEC, 1991. Council Regulation 2092/91 of 24 June 1991 on organic production of agricultural products and indications referring thereto on agricultural products and foodstuffs. OJ L 198, 22.7.1991, page 1.

EC, 1999. Council Regulation 1257/99 of 17 May 1999 on support for rural development from the European Agricultural Guidance and Guarantee Fund (EAGGF) and amending and repealing certain regulations. OJ L 160, 26.6.1999, page 80.

EC, 2001. Regulation (EC) No 761/2001 of the European parliament and of the council of 19 March 2001 allowing voluntary participation by organisations in a Community eco-management and audit scheme (EMAS). 0J L 114, 24.4.2001, page 1.

EC, 2009. The Farm Accountancy Data Network. Available from: http://ec.europa.eu/agriculture/rica/index_en.cfm

El Titi A., 1992. Integrated farming: an ecological farming approach in European agriculture. Outlook Agr 21:33-39.

Irving P., Moncrieff I., 2004. Managing the environmental impacts of land transport: integrating environmental analysis with urban planning. Sci Total Environ 334-335:47-59.

ISTAT, 2000. V Censimento dell'Agricoltura. ISTAT, Rome, Italy.

Knisel G., 1993. GLEAMS Groundwater Loading Effects of Agricultural Management Systems,Version 2.10. University of Georgia-Coastal Plain Experiment Station-Biological and Agricultural Engineering Dept. Publication No. 5. Tifton, GA, USA.

Landi R., 1999. Agronomia e Ambiente. Edagricole, Bologna, Italy.

Lazzerini G., 2001. Paragrafi 2.1-2, 3.1-2, 4.2.2-3, 5.3.2, 6.1-3-4, 4.1 con Rovai M. In: M. Buiatti (ed.) Contabilità ambientale in agricoltura - Toscana. Il Sole 24 ORE Spa, Roma, Italy.

Lazzerini G., Vazzana C., 2005. Indicatori agro-ambientali come strumenti di gestione aziendale e di valutazione della sostenibilità ambientale. Proc. 36th Nat. Meet. Italian Society of Agronomy, Foggia, Italy.

Lewis G., 1836. On experimental farms. Observations on the present state and future prospects of agriculture, illustrative of the advantages of an experimental farm. Q J Agr 7:538-547.

Lopez-Ridaura S., Masera 0., Astier M., 2002. Evaluating sustainability of complex socio-environmental systems: the MESMIS Framework. Ecol Indic 2:135-148.

Lotti A., 2006. Monitoring the connection Between Humans and the tainable development. Kluwer Academic Publ., Dordrecht, The Netherlands. 
Land: The Use of Indicators on Three Farms in Italy. Senior Essay for Major in Environmental Studies, Yale University, New Haven, CT, USA.

Mannion A.M., 1995. Agriculture and Environmental Change. Temporal and Spatial Dimensions. J. Wiley \& Sons, Ltd., Chichester, West Sussex, UK.

Manrique L.A., 1986. Land Erodibility Assessement Methodology. Manrique International Agrotech (MIAT). Available from: http://www.lava.net/manrique

Moriondo M., Pacini C., Trombi G., Vazzana C., Bindi M., 2010. Sustainability of dairy farming system in Tuscany in a changing climate. Eur J Agron 32:80-90.

Nicholls C.I., Altieri M.A., Dezanet A., Lana M., Feistauer D., Ouriques M., 2004. A Rapid, Farmer-Friendly Agroecological Method to Estimate Soil Quality and Crop Health in Vineyard Systems. Biodynamics 250: 33-39.

Pacini, G.C., 2003. An environmental-economic framework to support multi-objective policy-making. A farming systems approach implemented for Tuscany. PhD Degree Diss., Wageningen University, Wageningen, The Netherlands.

Pacini G.C., Lazzerini G., Migliorini P., Vazzana C., 2009. An indicatorbased framework to evaluate sustainability of farming systems: review of applications in Tuscany. Ital. J. Agron. 4:23-40.

Pacini C., Giesen G., Wossink A., Omodei-Zorini L., Huirne R., 2004a. The EU's Agenda 2000 reform and the sustainability of organic farming in Tuscany: ecological-economic modelling at field and farm level. Agr Syst 80:171-197.

Pacini C., Wossink A., Giesen G., Huirne R., 2004b. Ecological-economic modelling to support multi-objective policy making: a farming systems approach implemented for Tuscany. Agr Ecosyst Environ 102: 349-364.

Pacini C., Wossink A., Giesen G., Vazzana C., Huirne R., 2003. Evaluation of sustainability of organic, integrated and conventional farming systems: a farm and field-scale analysis. Agr Ecosyst Environ 95: 273-288.

Pacini C., Wossink A., Vazzana C., Omodei-Zorini L., 2000. Environmental accounting in agriculture: a theoretical overview with special reference to Tuscany. Proc. Nat. Meet. AAEA, Tampa, FL, USA.
Padovani L., Trevisan M., Capri E., 2004. A calculation procedure to assess potential environmental risk of pesticides at the farm level. Ecol Indic 4:111-123.

Pileri P., 1992. Interpretare l'ambiente - Gli indicatori di sostenibilità per il governo del territorio. Alinea Editrice, Firenze, Italy.

Regione Toscana, 2003. Piano di Azione Ambientale (PRAA) 2004-2006 della Regione Toscana.

Righi E., Dogliotti,S., Stefanini F.M., Pacini G.C., 2010. Capturing farm diversity at regional level to up-scale farm level impact assessment of sustainable development options. Agr Ecosyst Environ (In Press).

Schotman A., 1998. Tussen bos en houtwal: broedvogels in een Twents cultrallandscap. RIN-rapport 88/37, Leersum, The Netherlands.

Smeding F.W, 1995. Protocol natuurplan. Department of Ecological Agriculture, Wageningen University, Wageningen, The Netherlands.

Smith A.J., Dumanski J., 1994. FESLM: An International Framework for Evaluating Sustainable Land Management. World Soil Resources Report No. 73, FA0, Roma, Italy.

Stockle C.0., Donatelli M., Nelson R., 2003. CropSyst, a cropping systems simulation model. Eur J Agron 18: 289-307.

Van der Werf H.M.G., Petit J., 2002. Evaluation of the environmental impact of agriculture at the farm level: a comparison and analysis of 12 indicator-based methods. Agr Ecosyst Environ 1922: 1-15.

Van Mansvelt, J.D., van der Lubbe, M.J., 1999. Checklist for sustainable landscape management. Elsevier Science B.V., Amsterdam, The Netherlands.

Vazzana C., Raso E., Pieri S., 1997. Una nuova metodologia europea per la progettazione e gestione di agroecosistemi integrati ed ecologici: applicazione in un'area agricola Toscana. Riv Agron 31:423-440.

Vereijken P., 1994. Designing prototypes. Progress Report n.1 of the Research Network on integrated and ecological arable farming systems for EU and associated countries. AB-DLO, Wageningen, The Netherlands.

Vereijken P., 1999. Manual for prototyping integrated and ecological arable farming systems (I/EAFS) in interaction with pilot farms. AB-DLO, Wageningen, The Netherlands.

Weersink A., Jeffrey S., Pannell D., 2002. Farm-level modeling for bigger issues. Rev Agr Econ 24:123-140. 